\title{
Association of Obesity with Infertility among Pakistani Men: A Case Control Study
}

\author{
Nida Zahid ${ }^{1 *}$, Sarah Saleem ${ }^{1}$, Iqbal Azam ${ }^{1}$, Tariq Moatter ${ }^{2}$ \\ ${ }^{1}$ Department of Community Health Sciences, Aga Khan University, Karachi, Pakistan \\ ${ }^{2}$ Department of Pathology, Aga Khan University, Karachi, Pakistan \\ Email: ${ }^{*}$ ida.zahid@aku.edu, sarah.saleem@aku.edu, iqbal.azam@aku.edu, tariq.moatter@aku.edu
}

Received 14 June 2015; accepted 18 August 2015; published 21 August 2015

Copyright (C) 2015 by authors and Scientific Research Publishing Inc.

This work is licensed under the Creative Commons Attribution International License (CC BY).

http://creativecommons.org/licenses/by/4.0/

(c) (;) Open Access

\begin{abstract}
Background: The reported prevalence of infertility in Pakistan is $21 \%$ of which $35 \%$ is contributed by male factor. Male infertility has multifactorial etiologies ranging from modifiable to genetic risk factors. Among all the risk factors that may account for male infertility, obesity is one of the emerging public health problems. Therefore, the aim of the study was to determine the association of obesity with infertility in Pakistani men. Methods: We conducted a case control study. Cases were men with impaired semen parameters and controls did not have impaired semen parameters. Results: The final multivariable logistic regression model after adjusting for the effect of other variables revealed that with every $1 \mathrm{~kg} / \mathrm{m}^{2}$ increase in BMI the odds of being infertile was $6 \%$ higher as compared to being fertile (aOR = 1.06; 95\% CI = 1.01, 1.11). Moreover the odds of having education of higher secondary or above was 3 times greater among cases as compared with the controls $(O R=3.10 ; 95 \% C I=1.66,5.77)$. Furthermore the odds of having previous medical conditions increasing the risk of infertility was higher among cases as compared with the controls (OR = 3.07; 95\% CI = 1.63, 5.79). Conclusion \& recommendations: This study indicates that obesity is an important risk factor for male infertility. Moreover our findings also indicate that higher educational status and previous medical conditions are also associated with male infertility. Thus awareness can be raised through treating physicians and public health messages.
\end{abstract}

\section{Keywords}

Male Infertility, Obesity

\section{Introduction}

Infertility affects between 60 to 168 million people worldwide and majority of those suffering live in the devel-

\footnotetext{
*Corresponding author.
}

How to cite this paper: Zahid, N., Saleem, S., Azam, I. and Moatter, T. (2015) Association of Obesity with Infertility among Pakistani Men: A Case Control Study. Open Journal of Epidemiology, 5, 204-215. 
oping world [1]. The reported prevalence of infertility in Pakistan is $21 \%$ of which $35 \%$ is contributed by male factor [2] [3]. Despite of recent proliferation in the field of reproduction whereby infertility has lately been construed to be a serious global problem, there are several reasons why infertility is ignored in the developing countries, and social norms are one of the important reasons [1].

Historically, the work up for the infertile couples has focused primarily on the conditions of female although male infertility presents a particularly vexing clinical problem [4]. Male infertility has a wide range of etiologies ranging from hormonal imbalance, raised body temperature, local trauma, inflammation, infections, drugs, exposure to occupational and environmental toxins [5]. Reduction of these risk factors may help to restore or preserve natural fertility [6].

Among all the risk factors that may account for male infertility, obesity is one of the emerging public health problem [7], which is increasing at an alarming rate in both the developed and developing world [8]. In 2005, 400 million of the world's adult population was found to be obese. Moreover, if recent trends continue, by 2015, up to 700 million of the world's adult population will be obese [9]. In South Asia, including Pakistan the increase in obesity is due to rapid social and environmental changes causing increasing urbanization, changing lifestyles, higher energy density of diets, and decreased physical activity [7]. In Pakistani men, the Metroville Health Study (MHS) in 2006 reported a prevalence of $27 \%$ and $7.1 \%$ for overweight \& obesity respectively [10].

The relationship of obesity with male infertility has been largely ignored [11] and the focus has always been on the detrimental effects of obesity on health risks such as hypertension, cardiac disorders, diabetes and other chronic disorders [7]. The relationship of obesity with male infertility is likely to be multifactorial. Firstly hormonal changes play a very essential role [11]. It is the hypoandrogenism and increased Estradiol (E2) levels that result in low testosterone levels causing deleterious effects on the spermatogenesis [12]. Secondly obesity is often associated with decreased physical activity especially in occupations related to prolonged period of sitting [13], this may cause fat deposition not only in the abdominal area and thigh but also the scrotal area [14]. Fat deposition around the scrotal blood vessels may impair blood cooling and elevate the testicular temperature causing disruption of the semen parameters [15]. Evidence from different parts of the world such as Norway, Salt lake, Iceland, Finland, Qatar and Denmark have shown a significant association between obesity and male infertility [4] [10] [12]-[17].

Currently we believe that advanced technologies have diverted the attention of the treating physicians to expensive invasive treatments such as testicular biopsy, intrauterine insemination (IUI), in vitro fertilization (IVF) and intracytoplasmic sperm injection (ICSI) [6]. To the best of our knowledge, limited information is available about the modifiable risk factors for male infertility from Pakistani context. And therefore, for resource poor countries such as Pakistan, it is imperative to understand the prevailing modifiable risk factors causing male infertility whereby effective, cheaper and less invasive alternative approaches can be identified for its management and treatment.

Obesity is one of the emerging public health challenges and the relationship of obesity with male infertility has been largely ignored. Hence, the objective of our study was to determine the association of obesity with infertility among Pakistani men.

\section{Methods}

We conducted a case control study and after taking a written informed consent from the study participants, both the cases and controls were enrolled from Australian Concept Infertility Medical Centre (ACIMC) Karachi, Pakistan from January to March 2013 as shown in Figure 1. The rationale behind the selection of this study center was that ACIMC is the only Centre in Karachi having maximum load of infertile couples seeking infertility treatment as compared to the other infertility centers. The additional benefit of selecting this center was the representation of different ethnic and socio-economic groups, as infertile couples were referred here from the 7 sub branches of the center located in different provinces of Pakistan.

We required a minimum sample size of 200 cases and 200 controls (ratio of case to control of 1:1) in order to achieve $80 \%$ power, with an anticipated prevalence of risk factors among the controls ranging from $7 \%$ to $63 \%$ [18]-[23], with an expected odds ratio of 2.5 or more [11] [12] [18] [19] [21] [22] [24] [25] and a level of significance of $5 \%$. We were successful in achieving the target and the final sample size for the analysis of 201 cases and 200 controls.

The case and control status of study participants in our study was based on the semen parameters according to 


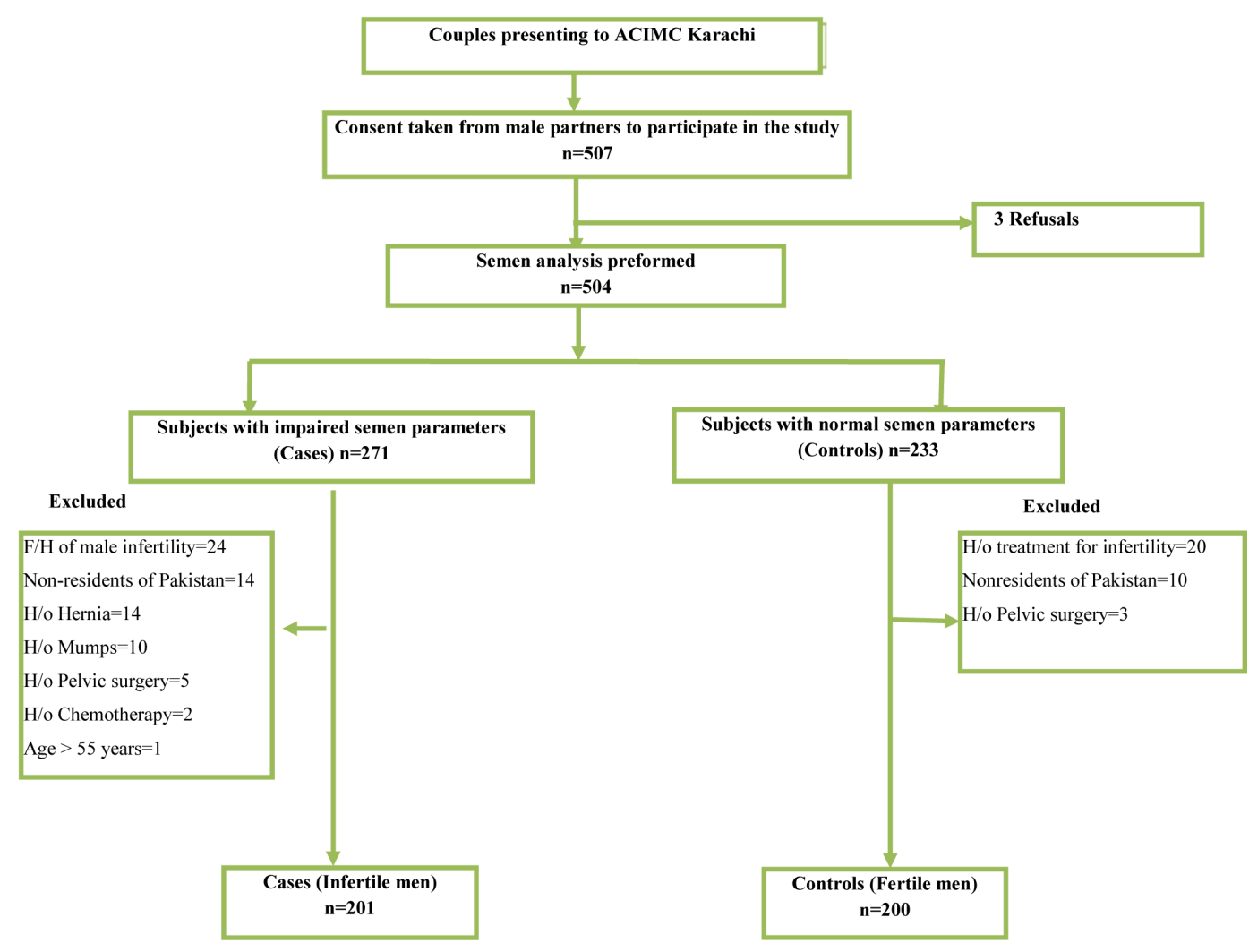

Figure 1. Flow of the study.

(WHO criteria "92") i.e. sperm concentration of $>20$ million/ml, semen volume of $>2 \mathrm{ml}$, motility of $>50 \%$ and morphology of $>30 \%$ normal forms [26]. Cases were men with impaired semen parameters and controls did not have impaired semen parameters. A screening tool was administered by the data collectors to identify the eligible subjects after the semen analysis was performed. The inclusion criteria for both the cases and controls were; 18 - 55 years old married Pakistani men, residing in Pakistan for at least the last 6 months or more at the time of interview, who had given the semen sample at the centre for laboratory examination and who consented to participate in the study. The exclusion criteria for both the cases and controls were; history of chemotherapy or radiotherapy: as sperm DNA damage occurs following even a single dose of these drugs [27], h/o pelvic surgery: as it blocks the internal sphincter of the bladder neck causing closure defect resulting in retrograde ejaculation [28], h/o inguinal herniorapphy: as it obstructs the vasdeferens and causes testicular atrophy as a result of impaired blood supply to the testis [29], h/o orchitic mumps: as it impairs the testicular function thereby causing impairment of the semen parameters [29] and family history of infertility: as a probability that the genetic cause for infertility would not be overruled. To avoid contamination of the results, an additional exclusion criterion for controls was men with the history of previous infertility treatment.

Once a patient was eligible to participate in the study a pretested structured questionnaire adapted and modified with the consent of the author [18] \& bodily measurement tools that is (height scale, weight scale, standard measuring tape and bioelectrical impedance analyser (for assessment of percent body fat)) were used to collect the information on the potential risk factors for impaired semen parameters.

The data was collected on the sociodemographic factors, obesity status, occupational exposures, tobacco usage, alcohol usage, and previous medical conditions such as scrotal/testicular trauma, varicocele, genitourinary infection, and prolonged fever of more than $38.5^{\circ} \mathrm{C}$ for consecutive 14 days in the past 3 months, usage of the medicines such as anti-depressants, antipsychotics, anti-hypertensive and diuretics.

Obesity status of the participants was ascertained by measuring their BMI, waist circumference and percentage body fat. BMI of the participants was assessed in $\mathrm{kg} / \mathrm{m}^{2}$ according to Asian cut off; $18-22.9 \mathrm{~kg} / \mathrm{m}^{2}$ for normal weight, $23-24.9 \mathrm{~kg} / \mathrm{m}^{2}$ for overweight $\& \geq 25 \mathrm{~kg} / \mathrm{m}^{2}$ for obesity [7] [30]. Waist circumference of the participants was assessed in centimeters (cm) according to Asian cut off; $<90 \mathrm{cms}$ for (average to moderate risk) 
and $\geq 90 \mathrm{cms}$ for (moderate to severe risk) [7] [30]. Percentage body fat was measured as a continuous variable as it has no specified cut offs [31]. The duration of occupational exposures was assessed (in hours/day) with a cutoff of more than 2 hours/day versus $\leq 2$ hours/day [32].

We performed analysis using Statistical Package for the Social Sciences (SPSS), version 19.0 \& STATA version 12. Descriptive statistics were computed for categorical variables by computing their frequencies and the distribution of quantitative variables was computed by their means and standard deviations. Odds ratio (ORs) with their 95\% confidence intervals (CIs) were reported using simple and multiple logistic regression.

All ethical considerations were taken into account. Firstly we obtained approval of the study protocol from Aga Khan University (AKU) ethical review committee (ERC). Permission was also gained from the study center Australian Concept Medical Infertility Centre (ACIMC) Karachi. Before any semen analysis, study was explained to the patients and their consent was obtained for participating as cases or controls. After the completion of the interview the data collector provided each and every participant with an informational brochure about the preventive measures for the possible risk factors for male infertility. For a better understanding of the participants the brochures were translated in Urdu. We reassured complete confidentiality to the study participants. The data was only accessible to the researchers and the responses were reported in group form and no individual case was identified.

\section{Results}

\subsection{Description of the Study Participants}

Table 1 presents the sociodemographic factors of the study participants. The mean age of the study subjects was similar in both the groups. Eleven per cent (11\%) of cases and $20 \%$ of controls never went to school, while more than half (55.7\%) of the cases and about one third (35.5\%) of the controls had education of higher secondary or above. A higher monthly income of $>25,000$ PKR ( $>$ \$251.5) was reported more by the cases (48.6\%) than controls (32\%).

The obesity status of the participants was assessed by measuring their BMI, waist circumference and percentage body fat as presented in Table 2. The mean BMI was higher in cases $26.45 \mathrm{~kg} / \mathrm{m}^{2}$ (SD 5.33) than controls $24.65 \mathrm{~kg} / \mathrm{m} 2$ (SD 4.39). Similarly cases as compared to the controls had a higher mean waist circumference and a higher mean percentage body fat.

Table 3 presents the risk exposures such as occupational factors, previous medical conditions increasing the

Table 1. Sociodemographic characteristics of the study subjects.

\begin{tabular}{|c|c|c|c|c|}
\hline $\begin{array}{c}\text { Sociodemographic } \\
\text { factors }\end{array}$ & \multicolumn{2}{|c|}{$\begin{array}{c}\text { Infertile men }(\mathbf{n}=\mathbf{2 0 1}) \\
\mathrm{n}(\%)\end{array}$} & \multicolumn{2}{|c|}{$\begin{array}{c}\text { Fertile men }(\mathbf{n}=\mathbf{2 0 0}) \\
\mathrm{n}(\%)\end{array}$} \\
\hline $18-29$ & 69 & $(34.3)$ & 77 & (38.5) \\
\hline $30-40$ & 115 & $(57.2)$ & 89 & $(44.5)$ \\
\hline$>40$ & 17 & $(8.5)$ & 34 & $(17.0)$ \\
\hline Age in years (Mean \pm SD) & 33.34 & $(6.04)$ & 33.74 & $(7.07)$ \\
\hline \multicolumn{5}{|l|}{ Educational status } \\
\hline No formal education & 22 & $(11.0)$ & 40 & $(20.0)$ \\
\hline Primary & 14 & $(7.0)$ & 24 & $(12.0)$ \\
\hline Secondary & 53 & $(26.3)$ & 65 & (32.5) \\
\hline Intermediate & 21 & $(10.4)$ & 11 & $(5.50)$ \\
\hline Bachelors or above & 91 & $(45.3)$ & 60 & $(30.0)$ \\
\hline \multicolumn{5}{|l|}{ Monthly Income (PKR) } \\
\hline$<10,000(<\$ 100.6)$ & 26 & $(13.0)$ & 27 & $(13.5)$ \\
\hline 10,000 - 15,000 (\$100.6 - 150.9) & 29 & $(14.4)$ & 41 & $(20.5)$ \\
\hline 16,000 - 25,000 (\$160.9 -251.5) & 48 & $(23.8)$ & 68 & $(34.0)$ \\
\hline 26,000 - 40,000 (\$261.5 - 402.4) & 45 & $(22.3)$ & 32 & $(16.0)$ \\
\hline$>40,000(>\$ 402.4)$ & 53 & $(26.3)$ & 32 & (16.0) \\
\hline
\end{tabular}


Table 2. Obesity status of the study subjects.

\begin{tabular}{|c|c|c|c|c|}
\hline Obesity measures & \multicolumn{2}{|c|}{ Infertile men $(n=201)$ n $(\%)$} & \multicolumn{2}{|c|}{ Fertile men $(n=200)$ n (\%) } \\
\hline Underweight $(<18)$ & 4 & $(2.0)$ & 12 & $(6.0)$ \\
\hline Normal weight (18 - 22.9) & 53 & $(26.4)$ & 54 & $(27.0)$ \\
\hline Overweight (23 - 24.9) & 29 & $(14.4)$ & 39 & (19.5) \\
\hline Obese $(\geq 25)$ & 115 & $(57.2)$ & 95 & $(47.5)$ \\
\hline BMI in $\mathrm{kg} / \mathrm{m}^{2}($ Mean \pm SD) & 26.45 & (5.33) & 24.65 & $(4.4)$ \\
\hline \multicolumn{5}{|l|}{ Waist Circumference (cm) } \\
\hline Average to moderate risk $(<90)$ & 85 & $(42.2)$ & 102 & $(51.0)$ \\
\hline \multicolumn{5}{|l|}{ Moderate to severe risk $(\geq 90)$} \\
\hline Waist circumference & 116 & $(57.7)$ & 98 & $(49.0)$ \\
\hline (Mean \pm SD) & 92.92 & $(12.8)$ & 88.70 & $(10.3)$ \\
\hline Percentage body (Mean \pm SD) & 22.82 & (8.7) & 20.22 & (7.5) \\
\hline
\end{tabular}

Table 3. Occupational exposures, previous medical conditions and use of addictives among study subjects.

\begin{tabular}{ccc}
\hline Variables & Infertile men $(\mathbf{n}=\mathbf{2 0 1}) \mathbf{n}(\mathbf{\%})$ & Fertile men $(\mathbf{n}=\mathbf{2 0 0}) \mathbf{n}(\mathbf{\%})$ \\
\hline Previous medical condition $^{*}$ & $40(20.0)$ & $17(8.5)$ \\
High risk occupational exposures & $159(79.1)$ & $172(86.0)$ \\
Prolong sitting & 133 & 8 \\
Heat & 6 & 4 \\
Solvents & 4 & 1 \\
Pesticides & 4 & 5 \\
Fumes & 9 & 2 \\
Metals & 3 & $100(50.0)$ \\
Tobacco usage & $74(36.8)$ & 5 \\
\hline
\end{tabular}

*Increasing the risk of infertility like testicular trauma, varicocoel, high temperature, genitourinary infections, and use of medicines.

risk of male infertility and use of addictive. Over all, these medical conditions were reported by $20 \%$ cases and $8.5 \%$ controls. Of these, testicular trauma ( $20 \%$ vs $0 \%$ ), varicocele ( $30 \%$ vs $17.6 \%)$, genitourinary infections ( $27.5 \%$ vs $11.7 \%)$, high grade fever ( $10 \%$ vs $5.8 \%)$, were commonly reported. Forty four percent $(44 \%)$ of cases took infertility treatment in the past which included homeopathic treatment (7.5\%), hakeemi (17.4\%) and allopathic (36.3\%). In both groups the use of medication included antihypertensive, antidepressants, antipsychotics and diuretics. Seventy nine percent of cases and $86 \%$ of controls mentioned being exposed to prolonged sitting, metals, fumes, pesticides, chemicals and heat. Furthermore tobacco usage in cases was reported by $36.8 \%$ as compared to $50 \%$ of controls. The proportion of participants with alcohol intake in both the groups were very few that is why it could not be analysed further.

We also assessed the semen parameters (concentration, count, motility \& morphology). As this was not the primary objective of our study hence we assessed these parameters on a subsample of 154 (77\%) infertile men enrolled in the study. Most commonly observed abnormalities were impairment in sperm motility (73.4\%), count (65.5\%), morphology (51.3\%) and consistency (5.8\%) as presented in Table 4(a). Common combination of abnormalities i.e. impaired count, motility \& morphology was observed in (27.9\%) of subjects and impaired count $\&$ motility in (13.0\%) of cases as presented in Table 4 (b).

\subsection{Univariate Analysis}

On univariate analysis as presented in Table 5 we observed that cases had a higher mean $\mathrm{BMI}$ in $\mathrm{kg} / \mathrm{m}^{2}(\mathrm{OR}=$ 
Table 4. (a) Semen parameters among infertile men ( $=154)$; (b) Semen parameters according to different combinations among infertile men $(\mathrm{n}=155)$.

(a)

\begin{tabular}{cc}
\hline Impaired Semen parameters $^{*}$ & $\mathrm{n}(\%)$ \\
\hline Abnormal consistency & $9(5.8)$ \\
Impaired Count & $101(65.5)$ \\
Impaired Motility & $113(73.4)$ \\
Impaired morphology & $79(51.3)$ \\
\hline
\end{tabular}

*Total does not add to $100 \%$ due to multiple responses.

(b)

\begin{tabular}{cc}
\hline Impaired Semen parameters* $^{*}$ & $\mathrm{n}(\%)$ \\
\hline Only Impaired motility & $30(19.5)$ \\
Only Impaired count & $23(14.9)$ \\
Only Impaired morphology & $13(8.4)$ \\
Only Abnormal consistency & $0(0.0)$ \\
Impaired count, motility \& morphology & $43(27.9)$ \\
Impaired count \& motility & $20(13.0)$ \\
Impaired motility \& morphology & $13(8.4)$ \\
Impaired consistency, count, motility \& morphology & $5(3.2)$ \\
Impaired count \& morphology & $3(1.9)$ \\
Impaired consistency \& count & $1(0.6)$ \\
Impaired consistency \& motility & $1(0.6)$ \\
Impaired consistency, count \& motility & $1(0.6)$ \\
Impaired consistency, count \& morphology & $1(0.6)$ \\
\hline
\end{tabular}

Table 5. Univariate Aanlysis for factors associated with male infertility.

\begin{tabular}{|c|c|c|c|}
\hline Variables & Infertile men $(n=201)$ n (\%) & Fertile men $(n=200)$ n $(\%)$ & Unadjusted OR (95\% CI) \\
\hline $\mathrm{BMI}$ in $\mathrm{Kg} / \mathrm{m}^{2}($ Mean $\pm \mathrm{SD})$ & $26.45(5.33)$ & 24.65 (4.39) & $1.08(1.04,1.13)$ \\
\hline Waist circumference in $\mathrm{cm}$ (Mean \pm SD) & $92.92(12.81)$ & $88.70(10.33)$ & $1.03(1.01,1.05)$ \\
\hline Percentage body fat (Mean \pm SD) & $22.82(8.67)$ & $20.22(7.49)$ & $1.04(1.02,1.07)$ \\
\hline \multicolumn{4}{|l|}{ Educational status } \\
\hline No formal education & 22 (10.9) & $45(22.5)$ & 1 \\
\hline Up to secondary & 67 (33.3) & $84(42.0)$ & $1.63(0.89,2.98)$ \\
\hline Higher secondary or above & $112(55.7)$ & $71(35.5)$ & $3.23(1.78,5.82)$ \\
\hline \multicolumn{4}{|l|}{ Monthly income (PKR) } \\
\hline$<10000(<100.6)$ & $26(13.0)$ & $27(13.5)$ & 1 \\
\hline $10,000-15,000(\$ 100.6-150.9)$ & 48 (23.9) & $68(34.0)$ & $0.73(0.38,1.41)$ \\
\hline $16,000-24,000(\$ 160.9-241.4)$ & $50(24.9)$ & $52(26.0)$ & $0.99(0.51,1.94)$ \\
\hline$\geq 25,000(\$ 251.5)$ & 77 (38.3) & $53(26.5)$ & $1.51(0.79,2.87)$ \\
\hline \multicolumn{4}{|l|}{ Previous medical conditions ${ }^{*}$} \\
\hline No & $161(80.0)$ & $183(91.5)$ & 1 \\
\hline Yes & $40(20.0)$ & $17(8.50)$ & $2.67(1.46,4.90)$ \\
\hline \multicolumn{4}{|l|}{ High risk occupational exposures } \\
\hline$\leq 2 \mathrm{~h} /$ day & $83(41.3)$ & $88(44.0)$ & 1 \\
\hline$>2 \mathrm{~h} /$ day & $118(58.7)$ & $112(56.0)$ & $1.12(0.75,1.66)$ \\
\hline \multicolumn{4}{|l|}{ Tobacco use } \\
\hline No & $127(63.2)$ & $100(50.0)$ & 1 \\
\hline Yes & 74 (36.8) & $100(50.0)$ & $0.58(0.39,0.87)$ \\
\hline
\end{tabular}

*Increasing the risk of infertility like testicular trauma, varicocoel, high temperature, genitourinary infections, and use of medicines. 
1.08; 95\% CI = 1.04 - 1.13), a higher mean waist circumference in $\mathrm{cm}(\mathrm{OR}=1.03$; 95\% CI $=1.01-1.05)$ and a higher mean percentage body fat $(\mathrm{OR}=1.04 ; 95 \% \mathrm{CI}=1.02-1.07)$ as compared to controls.

The odds of having an educational status of higher secondary or above was 3 times greater among cases as compared to the controls $(\mathrm{OR}=3.23 ; 95 \% \mathrm{CI}=1.78-5.82)$. Furthermore the odds of having previous medical conditions increasing the risk of infertility was higher among cases as compared to the controls ( $\mathrm{OR}=2.67 ; 95 \%$ $\mathrm{CI}=1.46-4.90)$.

Occupational exposures, monthly income \& tobacco usage were also associated with male infertility at $\mathrm{P}$ value $\leq 0.2$ and were included in the multivariable analysis.

\subsection{Multivariable Analysis}

Table 6 presents the final logistic regression model which includes: mean BMI in $\left(\mathrm{kg} / \mathrm{m}^{2}\right)$, educational status of the subjects \& previous medical conditions increasing the risk of male infertility. It was observed that after adjusting for the other covariates with every $1 \mathrm{~kg} / \mathrm{m}^{2}$ increase in BMI the odds of being a case was $6 \%$ higher as compared to being a control $(\mathrm{aOR}=1.06 ; 95 \% \mathrm{CI}=1.01,1.11)$. The odds of having an educational status of higher secondary or above was 3 times greater among cases as compared to the controls $(\mathrm{OR}=3.10$; $95 \% \mathrm{CI}=$ 1.66, 5.77). Furthermore the odds of having previous medical conditions increasing the risk of infertility was higher among cases as compared to the controls $(\mathrm{OR}=3.07 ; 95 \% \mathrm{CI}=1.63,5.79)$. There was no interaction and confounding found in the model. The Pearson goodness of fit test for the final model was $\chi^{2}=329.44, \mathrm{p}=$ $0.52)$.

Table 6. Multivariable Aanlysis for factors associated with male infertility.

\begin{tabular}{|c|c|c|c|}
\hline Variables & Infertile men $(n=201)$ n (\%) & Fertile men $(n=200) n(\%)$ & Adjusted OR (95\% CI) \\
\hline $\mathrm{BMI}$ in $\mathrm{Kg} / \mathrm{m}^{2}($ Mean $\pm \mathrm{SD})$ & $26.45(5.3)$ & $24.65(4.4)$ & $1.06(1.01,1.11)$ \\
\hline \multicolumn{4}{|l|}{ Educational status } \\
\hline No formal education & $22(10.9)$ & $45(22.5)$ & 1 \\
\hline Up to secondary & 67 (33.3) & $84(42.0)$ & $1.67(0.89,3.12)$ \\
\hline Higher secondary or above & $112(55.7)$ & $71(35.5)$ & $3.10(1.66,5.77)$ \\
\hline \multicolumn{4}{|l|}{ Previous medical conditions ${ }^{*}$} \\
\hline No & $161(80.0)$ & $183(91.5)$ & 1 \\
\hline Yes & $40(20.0)$ & $17(8.5)$ & $3.07(1.63,5.79)$ \\
\hline
\end{tabular}

*Increasing the risk of infertility like testicular trauma, varicocoel, high temperature, genitourinary infections, and use of medicines.

\section{Discussion}

The typical profile of an infertile male presenting to ACIMC was of "an educated, obese person, with history of a medical condition exposing him to the risk of developing infertility".

Obesity is one of the emerging public health problems [7]. The prevalence of obesity is increasing at an alarming level in both developed and developing countries [8]. It is known to have detrimental effects on health risks such as hypertension, cardiac disorders, diabetes and other chronic disorders [7]. But unfortunately the interest in the detrimental effects of obesity on reproductive functions is very recent [11]. Our results support the adverse effect of obesity on semen parameters which is consistent with the findings from other studies [4] [10] [12]-[17].

Moreover in obese men, it is the aromatization in fatty tissues that increases the estrogen levels leading to hypoandrogenemia and altered semen parameters [33] and it is for this reason why percentage body weight is an ideal parameter to assess deposition of fatty tissue to ascertain obesity. But unfortunately this method of measurement has often not been used because of the complexity of the procedure and the cost of the device bioelectrical impedance analyser (BIA). In our study we were fortunate enough to be able to measure the percentage body fat by the device BIA along with the BMI and waist circumference. All these methods of assessing obesity showed significant association of obesity with male infertility. However, for our final model for multivariable analysis we chose BMI as an indicator for obesity over percentage body fat, because measuring BMI is convenient in a developing country's setting and can easily be determined at a larger scale by public health personnel [34]. 
Moreover literature suggests that obesity is often associated with decreased physical activity [13]. This causes fat deposition not only in the abdominal area and thighs but also in the scrotal area resulting in elevated testicular temperature and disrupting the semen parameters [13] [15]. We assume that in our study cases having a higher educational status and a higher BMI as compared to the controls, may be involved in occupations predisposing them to decreased physical activity which may have further contributed to impairment in the semen parameters.

Furthermore, certain medical conditions such as testicular injury, varicocele, genitourinary infections, constant temperature of $>38.5$ degree centigrade for 10 - 14 days, and use of medications can expose men to higher risk of infertility [21] [35]-[38]. In our study sample 20 percent of cases as opposed to $8.5 \%$ of controls had such conditions. The association between these conditions and infertility was statistically significant in our study which was consistent with the findings from other studies too [15] [39] [40].

In our study sample, majority of the cases had a higher educational status whereas majority of the controls comparatively had a lower educational status. Evidence from USA too suggests that men seeking infertility treatment compared to those not seeking infertility treatment had a higher educational status of college or above $(\mathrm{OR}=2.7,95 \% \mathrm{CI}=1.4-5.0)$ [34]. In a patriarchal society like ours, women is held responsible for child bearing and bears the burden of being infertile irrespective of who is responsible for the condition and the work up of an infertile couple is primarily focused on the female's condition [2] [4]. We believe that in our study sample the higher educational status among the cases made them more aware to accept their condition and seek the treatment. In our study sample, controls that were less educated may have been aware of the infertile status of their wives and felt no stigma for being investigated. Unfortunately we did not ask regarding the fertility status of female partners and the type of infertility for which the couple was being investigated i.e. primary or secondary.

Our study revealed an insignificant association between high risk occupational exposures and male infertility; this could be due to the fact that very few of our study subjects were in jobs exposing them to metals, fumes, chemicals and pesticides. However, there is inconsistency of data regarding these exposures in relation to male infertility hence suggesting further exploration of these factors [18] [19] [21] [41]-[45].

\subsection{Strengths}

There were several strengths of our study. Firstly recruitment of participants was based on the semen analysis report which was a robust method of evaluation, leading to a decreased chance of misclassification of the outcome status of the participants.

Secondly we ascertained obesity by various measures such as BMI, waist circumference and percentage body fat, which again reduced the chances of misclassification of the exposure status of the participants.

Although we collected our study sample from an urban clinic so we missed information on certain known exposures such chemicals, pesticides etc. but we believe that the results could be generalized to the urban populations.

\subsection{Limitations}

The limitations of our study were: There were insufficient responses regarding certain occupational exposure and addictives. We believe that this was due to self-reported information given by the participants that must have predisposed them to recall limitation and reporting bias. Therefore, in future studies rigorous methodology should be used to assess this risk factor.

Secondly we could not evaluate chromosomal factors due to economic constraints. We recommend that future research should focus on the exploration of genetic factors in association with male infertility as the treatment of infertility by artificial reproductive techniques (ART) is very expensive, and the success rates reported by European Society of Human Reproduction and Embryology (ESHRE) in 2005, for in vitro fertilization (IVF) was 30.3\%, Intracytoplasmic sperm injection (ICSI) was 30.9\% and Intrauterine insemination (IUI) was 12.6\% [46] [47].

Genetic defects in sperms such as aneuploidy, mutations, structural variations and DNA fragmentation are commonly found in men with impaired semen parameters. This increases the failure rate of the treatment by artificial reproductive techniques (ART) [48]. The ascertainment of genetic factors during the course of treatment by ART is not a common practice, thereby increasing the chances of failure of this expensive treatment. Therefore this signifies the importance of exploration of this factor during the course of treatment of infertility. 


\section{Conclusions and Recommendations}

This study indicates that obesity, an emerging public health problem, is an important risk factor for male infertility. It not only increases the risk of hypertension, cardiac disorders, diabetes and other chronic disorders, but also contributes to causing infertility in men. Moreover, our findings also indicated that higher educational status and previous medical conditions were also associated with male infertility.

Therefore, at policy level we recommend that health professionals should be educated about the modifiable risk factors associated with male infertility. Males with previous medical conditions as well as men in general should be made aware of being extra cautious for monitoring their body weight by increasing their physical activities. This may help in the restoration of the natural fertility with minimal expenses thereby reducing the economic and psychological burden on the society.

Furthermore, genetic abnormalities in sperms increase the failure rates of treatment by ART, hence this indicates a desperate need of exploration of these factors.

\section{Authors Contribution}

NZ: was the principle investigator of the study and conducted this study as a part of her MSc Epidemiology \& Biostatistics thesis project. She carried out the study conception, design, data analysis, interpretation of data and drafted the manuscript.

SS: Professor at the Department of Community Health Sciences Aga khan University Karachi, Pakistan was the thesis supervisor, she has made substantial contribution in conception and design, interpretation of data, has been involved in drafting the manuscript and revising it critically and has given final approval of the version to be published.

IA: Assistant Professor at the Department of Community Aga Khan University Karachi, Pakistan was the thesis committee member. He has made substantial contributions to conception and design, sample size estimation, data analysis and interpretation of data and has given final approval of the version to be published.

TM: Professor at the Department of Pathology Aga Khan University Karachi, Pakistan was the thesis committee members. He has made contribution in the conception of the study and has given final approval of the version to be published.

All authors read and approved the final manuscript.

\section{Acknowledgements}

Grant for this study was provided by Aga Khan University Community Health Sciences Department Student Fund. We thank all the research staff for their assistance. We specially acknowledge Dr Romaina Iqbal (Associate professor at the Department of Community Health Sciences, AKUH) for providing us with the Bioelectrical Impedance Analyzer. We are also grateful to Mr Mohammad Tahir (Senior Embryologist at ACIMC) for his cooperation throughout the study period.

\section{References}

[1] Evens, E.M. (2004) A Global Perspective on Infertility: An Under Recognized Public Health Issue. Carolina Papers in International Health, No. 18. University Center North Carolina at Chapel Hill.

[2] Sami, N. and Ali, T.S. (2006) Psycho-Social Consequences of Secondary Infertility in Karachi. Journal-Pakistan Medical Association, 56, 19.

[3] Saeed, S., Khan, F.A., Rahman, S.B., Khan, D.A. and Ahmad, M. (1994) Biochemical Parameters in Evaluation of Oligospermia. The Journal of the Pakistan Medical Association, 44, 137.

[4] Zakai, F., Uddin, S., Akram, M., Mohiuddin, E., Hannan, A. and Usmanghani, K. (2011) Introduction to Male Infertility. Journal of Medicinal Plants Research, 5, 5936-5945.

[5] Wang, R. and Allison, J. (2005) Male Infertility. Science, 308, 1466-1469.

[6] McLachlan, R.I. and Krausz, C. (2011) Clinical Evaluation of the Infertile Male: New Options, New Challenges. Asian Journal of Andrology, 14, 3-5. http://dx.doi.org/10.1038/aja.2011.73

[7] Nanan, D.J. (2002) The Obesity Pandemic-Implications for Pakistan. The Journal of the Pakistan Medical Association, 52, 342-346.

[8] Jafar, T.H., Chaturvedi, N. and Pappas, G. (2006) Prevalence of Overweight and Obesity and Their Association with 
Hypertension and Diabetes Mellitus in an Indo-Asian Population. Canadian Medical Association Journal, 175, 10711077. http://dx.doi.org/10.1503/cmaj.060464

[9] Ramachandran, A. and Snehalatha, C. (2010) Rising Burden of Obesity in Asia. Journal of Obesity, 2010, Article ID: 868573.

[10] Dennis, B., Aziz, K., She, L., Faruqui, A.M., Davis, C.E., Manolio, T.A., Burke, G.L. and Aziz, S. (2006) High Rates of Obesity and Cardiovascular Disease Risk Factors in Lower Middle Class Community in Pakistan: The Metroville Health Study. Journal of Pakistan Medical Association, 56, 267-272.

[11] Hammoud, A.O., Gibson, M., Peterson, C.M., Meikle, A.W. and Carrell, D.T. (2008) Impact of Male Obesity on Infertility: A Critical Review of the Current Literature. Fertility and Sterility, 90, 897-904. http://dx.doi.org/10.1016/j.fertnstert.2008.08.026

[12] Hammoud, A.O., Wilde, N., Gibson, M., Parks, A., Carrell, D.T. and Meikle, A.W. (2008) Male Obesity and Alteration in Sperm Parameters. Fertility and Sterility, 90, 2222-2225. http://dx.doi.org/10.1016/j.fertnstert.2007.10.011

[13] Ivell, R. (2007) Lifestyle Impact and the Biology of the Human Scrotum. Reproductive Biology and Endocrinology, 5, 15. http://dx.doi.org/10.1186/1477-7827-5-15

[14] Shafik, A. and Olfat, S. (1981) Lipectomy in the Treatment of Scrotal Lipomatosis. British Journal of Urology, 53, 5561. http://dx.doi.org/10.1111/j.1464-410X.1981.tb03129.x

[15] Sharpe, R.M. (2010) Environmental/Lifestyle Effects on Spermatogenesis. Philosophical Transactions of the Royal Society B: Biological Sciences, 365, 1697-1712. http://dx.doi.org/10.1098/rstb.2009.0206

[16] Gill, T. (2006) Epidemiology and Health Impact of Obesity: An Asia Pacific Perspective. Asia Pacific Journal of Clinical Nutrition, 15, 3-14.

[17] Chavarro, J.E., Toth, T.L., Wright, D.L., Meeker, J.D. and Hauser, R. (2010) Body Mass Index in Relation to Semen Quality, Sperm DNA Integrity, and Serum Reproductive Hormone Levels among Men Attending an Infertility Clinic. Fertility and Sterility, 93, 2222-2231. http://dx.doi.org/10.1016/j.fertnstert.2009.01.100

[18] De Fleurian, G., Perrin, J., Ecochard, R., Dantony, E., Lanteaume, A., Achard, V., Grillo, J.M., Guichaoua, M.R., Botta, A. and Sari-Minodier, I. (2009) Occupational Exposures Obtained by Questionnaire in Clinical Practice and Their Association with Semen Quality. Journal of Andrology, 30, 566-579. http://dx.doi.org/10.2164/jandrol.108.005918

[19] He, J., Liu, H.C., Yu, W.Z. and Zou, H.Y. (2008) Semen Analysis of Sterile Patients among Occupational Computermen. National Journal of Andrology, 14, 914.

[20] Cherry, N., Labreche, F., Collins, J. and Tulandi, T. (2001) Occupational Exposure to Solvents and Male Infertility. Occupational and Environmental Medicine, 58, 635-640. http://dx.doi.org/10.1136/oem.58.10.635

[21] Magnusdottir, E.V., Thorsteinsson, T., Thorsteinsdottir, S., Heimisdottir, M. and Olafsdottir, K. (2005) Persistent Organochlorines, Sedentary Occupation, Obesity and Human Male Subfertility. Human Reproduction, 20, 208-215. http://dx.doi.org/10.1093/humrep/deh569

[22] Chia, S.-E. and Tay, S.-K. (2001) Occupational Risk for Male Infertility: A Case-Control Study of 218 Infertile and 227 Fertile Men. Journal of Occupational and Environmental Medicine, 43, 946-951. http://dx.doi.org/10.1097/00043764-200111000-00004

[23] Noruziyan, Z., Roghanian, R., Hosseinzadeh, S., Golbang, N. and Nasr Esfahani, M.H. (2012) Possible Role of Chlamydia trachomatis in the Male Partner of Infertile Couples. Comparative Clinical Pathology, 22, 421-424.

[24] Akl, E.A., Gaddam, S., Gunukula, S.K., Honeine, R., Jaoude, P.A. and Irani, J. (2010) The Effects of Waterpipe Tobacco Smoking on Health Outcomes: A Systematic Review. International Journal of Epidemiology, 39, 834-857. http://dx.doi.org/10.1093/ije/dyq002

[25] Greendale, G.A., Haas, S.T., Holbrook, K., Walsh, B., Schachter, J. and Phillips, R.S. (1993) The Relationship of Chlamydia trachomatis Infection and Male Infertility. American Journal of Public Health, 83, 996-1001. http://dx.doi.org/10.2105/AJPH.83.7.996

[26] Menkveld, R., Wong, W.Y., Lombard, C.J., Wetzels, A.M.M., Thomas, C.M.G., Merkus, H.M.W.M. and SteegersTheunissen, R.G.P.M. (2001) Semen Parameters, Including WHO and Strict Criteria Morphology, in a Fertile and Subfertile Population: An Effort towards Standardization of In-Vivo Thresholds. Human Reproduction, 16, 1165-1171. http://dx.doi.org/10.1093/humrep/16.6.1165

[27] Agarwal, A. and Said, T.M. (2003) Role of Sperm Chromatin Abnormalities and DNA Damage in Male Infertility. Human Reproduction Update, 9, 331-345. http://dx.doi.org/10.1093/humupd/dmg027

[28] Rojas-MartÃnez, R., Aguilar-Salinas, C.A., Jiménez-Corona, A., Gómez-Pérez, F.J., Barquera, S.N. and LazcanoPonce, E. (2012) Prevalence of Obesity and Metabolic Syndrome Components in Mexican Adults without Type 2 Diabetes or Hypertension. Salud Pública de México, 54, 7-12.

[29] Hofny, E.R.M., Ali, M.E., Abdel-Hafez, H.Z., Kamal, E.E.-D., Mohamed, E.E., Abd El-Azeem, H.G. and Mostafa, T. 
(2010) Semen Parameters and Hormonal Profile in Obese Fertile and Infertile Males. Fertility and Sterility, 94, 581-584. http://dx.doi.org/10.1016/j.fertnstert.2009.03.085

[30] James, P.T., Leach, R., Kalamara, E. and Shayeghi, M. (2001) The Worldwide Obesity Epidemic. Obesity Research, 9, 228S-233S. http://dx.doi.org/10.1038/oby.2001.123

[31] Flegal, K.M., Shepherd, J.A., Looker, A.C., Graubard, B.I., Borrud, L.G., Ogden, C.L., Harris, T.B., Everhart, J.E. and Schenker, N. (2009) Comparisons of Percentage Body Fat, Body Mass Index, Waist Circumference, and Waist-Stature ratio in Adults. The American Journal of Clinical Nutrition, 89, 500-508. http://dx.doi.org/10.3945/ajcn.2008.26847

[32] Bujan, L., Daudin, M., Charlet, J.-P., Thonneau, P. and Mieusset, R. (2000) Increase in Scrotal Temperature in Car Drivers. Human Reproduction, 15, 1355-1357. http://dx.doi.org/10.1093/humrep/15.6.1355

[33] Akinloye, O. and Truter, E.J. (2011) A Review of Management of Infertility in Nigeria: Framing the Ethics of a National Health Policy. International Journal of Women's Health, 3, 265-275. http://dx.doi.org/10.2147/IJWH.S20501

[34] MacDonald, A.A., Herbison, G.P., Showell, M. and Farquhar, C.M. (2010) The Impact of Body Mass Index on Semen Parameters and Reproductive Hormones in Human Males: A Systematic Review with Meta-Analysis. Human Reproduction Update, 16, 293-311. http://dx.doi.org/10.1093/humupd/dmp047

[35] Pasqualotto, F.F., Lucon, A.M., Sobreiro, B.P., Pasqualotto, E.B. and Arap, S. (2004) Effects of Medical Therapy, Alcohol, Smoking, and Endocrine Disruptors on Male Infertility. Revista do Hospital das Clínicas, 59, 375-382. http://dx.doi.org/10.1590/s0041-87812004000600011

[36] Ramalho-Santos, J., Amaral, S. and Oliveira, P.J. (2008) Diabetes and the Impairment of Reproductive Function: Possible Role of Mitochondria and Reactive Oxygen Species. Current Diabetes Reviews, 4, 46-54. http://dx.doi.org/10.2174/157339908783502398

[37] Dohle, G.R., Colpi, G.M., Hargreave, T.B., Papp, G.K., Jungwirth, A. and Weidner, W. (2005) EAU Guidelines on Male Infertility. European Urology, 48, 703-711. http://dx.doi.org/10.1016/j.eururo.2005.06.002

[38] Schiff, J.D., RamÃ-rez, M.L. and Bar-Chama, N. (2007) Medical and Surgical Management Male Infertility. Endocrinology and Metabolism Clinics of North America, 36, 313-331. http://dx.doi.org/10.1016/j.ecl.2007.03.003

[39] Håkonsen, L.B., Thulstrup, A.M., Aggerholm, A.S.R., Olsen, J.R., Bonde, J.P., Andersen, C.Y., Bungum, M., Ernst, E.H., Hansen, M.L. and Ernst, E.H. (2011) Does Weight Loss Improve Semen Quality and Reproductive Hormones? Results from a Cohort of Severely Obese Men. Reproductive Health, 8, 24. http://dx.doi.org/10.1186/1742-4755-8-24

[40] Abdalla, N.M. (2011) Epidemiology of Infertility in Gezira Region, Central of Sudan. Research Journal of Medical Sciences, 5, 56-60. http://dx.doi.org/10.3923/rjmsci.2011.56.60

[41] Gracia, C.R., Sammel, M.D., Coutifaris, C., Guzick, D.S. and Barnhart, K.T. (2005) Occupational Exposures and Male Infertility. American Journal of Epidemiology, 162, 729-733. http://dx.doi.org/10.1093/aje/kwi269

[42] Jensen, T.K., Bonde, J.P. and Joffe, M. (2006) The Influence of Occupational Exposure on Male Reproductive Function. Occupational Medicine, 56, 544-553. http://dx.doi.org/10.1093/occmed/kql116

[43] Sharpe, R.M. (2000) Lifestyle and Environmental Contribution to Male Infertility. British Medical Bulletin, 56, 630642. http://dx.doi.org/10.1258/0007142001903436

[44] Meeker, J.D., Rossano, M.G., Protas, B., Diamond, M.P., Puscheck, E., Daly, D., Paneth, N. and Wirth, J.J. (2008) Cadmium, Lead, and Other Metals in Relation to Semen Quality: Human Evidence for Molybdenum as a Male Reproductive Toxicant. Environmental Health Perspectives, 116, 1473-1479. http://dx.doi.org/10.1289/ehp.11490

[45] de la Calle, J.F.V., Rachou, E., le Martelot, M.-T.R.S., Ducot, B.A., Multigner, L. and Thonneau, P.F. (2001) Male Infertility Risk Factors in a French Military Population. Human Reproduction, 16, 481-486. http://dx.doi.org/10.1093/humrep/16.3.481

[46] Ali, S., Sophie, R., Imam, A.M., Khan, F.I., Ali, S.F., Shaikh, A. and Farid-ul-Hasnain, S. (2011) Knowledge, Perceptions and Myths Regarding Infertility among Selected Adult Population in Pakistan: A Cross-Sectional Study. BMC Public Health, 11, 760. http://dx.doi.org/10.1186/1471-2458-11-760

[47] Goossens, V., Bhattacharya, S., Ferraretti, A.P., Kupka, M.S., de Mouzon, J., Nygren, K.G., Glozheni, O., Candeur, M., Kyurkchiev, S. and Radakovic, B. (2009) Assisted Reproductive Technology and Intrauterine Inseminations in Europe, 2005: Results Generated from European Registers by ESHRE. ESHRE. The European IVF Monitoring Programme (EIM), for the European Society of Human Reproduction and Embryology (ESHRE). Human Reproduction, 24, 12671287. http://dx.doi.org/10.1093/humrep/dep035

[48] Aston, K.I. and Conrad, D.F. (2013) The Sperm Genome: Effect of Aneuploidies, Structural Variations, Single Nucleotide Changes, and DNA Damage on Embryogenesis. In: Carrell, D.T., Ed., Paternal Influences on Human Reproductive Success, Cambridge University Press, Cambridge, 6-15. 


\section{Abbreviations}

(ACIMC) Australian Concept Infertility Medical Centre, (BMI) Body Mass Index, (aOR)Adjusted Odds Ratio, (MHS) Metroville Health Study, (E2) Estradiol, (SHBG) Sex Hormone-Binding Globulin, (IUI) Intrauterine Insemination, (IVF) In Vitro Fertilization, (ICSI) Intracytoplasmic Sperm Injection, (AKU) The Aga Khan University, (ERC) Ethical Review Committee, (WHO) World Health Organization, (SPSS) Statistical Package for the Social Sciences, (ORs) Odds ratio, (CIs) Confidence intervals, (BIA) Bioelectrical impedance analyser, (ART) artificial reproductive techniques, (ESHRE) European Society of Human Reproduction and Embryology. 